\title{
A ABCD E O SCIELO
}

\section{The ABCD and the SciELO}

ABCDDV/546

Habr-Gama A. A ABCD e o SciELO. ABCD Arq Bras Cir Dig 2007;20(3):141-2.

DESCRITORES - Publicações periódicas. Sistemas em linha. Interface usuário-computador.

\section{INTRODUÇÃO}

Qual é o aspecto pontual que valoriza um diamante, ou seja, entre diamantes de mesmo tamanho, cor, brilho e lapidação, como se escolheria o melhor? Qual vale mais?

A resposta é: a mensuração de sua pureza, feita através de processos internacionalmente aceitos e criados pela comunidade de especialistas em gemas.

Qual é o aspecto pontual que valoriza o vinho, ou seja, a mesma vinícola coloca o mesmo preço em uma mesma varietal ano após ano?

A resposta é: não, pois o aspecto pontual de valorização é a safra que representa a coincidência ocasional em anos especiais da somatória de vários fatores importantes para a qualidade do vinho, onde o nível pluviométrico e o momento das chuvas, a temperatura e a sua duração, o momento em que estes eventos ocorrem e o desenvolvimento da vinha, coincidem com o desabrochar dos vinhedos. Essa coincidência promove maior concentração interna do suco da uva que dignificará o vinho a ser por ela produzido.

Então, qual é o aspecto pontual na valorização de uma revista científica?

A resposta é: citação! Por estranho que isto inicialmente possa parecer, são as referências citadas ao final de cada artigo original, que contadas numericamente e cruzadas com as revistas referidas, valem como fator pontual na mensuração de qualidade nas publicações científicas. Assim, os periódicos mais citados nas refêrencias bibliográficas em um referido ano são considerados melhores, e daí surge o "ranqueamento" quando se compara as revistas entre si.

Pode não agradar à primeira vista, mas medir qualidade é sempre tarefa muito difícil e controversa.

\footnotetext{
* Presidente do Colégio Brasileiro de Cirurgia Digestiva - CBCD
}

Endereço para correspondência: Colégio Brasileiro de Cirurgia Digestiva, e-mail: cbcd@cbcd.org.br
Mas como fazer essa mensuração?

É trabalho de gigantes, hoje materializado pelo Journal of Citation Report- JCR elaborado pelo Instituto para Informação Científica-ISI (www.isinet.com) que, dos periódicos listados no Index Medicus/MEDLINE, faz o "ranqueamento" de 8.000, divididos em 230 categorias diferentes provindos de 60 países, cruzando anualmente todos as referências dessas revistas. Dividindo-se o número destas citações pelo total de artigos publicados por determinado periódico naquele ano, obtém-se um fator que é chamado de Fator de Impacto do periódico pesquisado. Esta metodologia, usada igualmente para todas as revistas, permite escalonamento de qualidade entre elas e resulta no JCR, base internacional para medir qualidade das publicações científicas.

Evidentemente, há um limite de revistas que podem ser incluídas para análise e este é sempre menor que o universo das publicações. Com isto, a grande parte dos periódicos do mundo em desenvolvimento fica fora do sistema. É o que acontece com o Brasil que possui incluídas no JCR somente 15 revistas (de todas as áreas do conhecimento e não somente da área da saúde), de acordo com o JCR de 2001 .

Contudo, a nossa necessidade de qualificação é a mesma que a de qualquer outra parte do mundo, pois em situações tais como concursos públicos, avaliações de currículos para progressão de cargo e salários, avaliações das escolas médicas, liberação de fomento para pesquisa - dentre outras tantas circunstâncias -, há necessidade de indicadores de qualidade justos, que expressem a real situação competitiva e que, fundamentalmente, sejam iguais para todos.

Para preencher esta lacuna na realidade brasileira, surgiu o Projeto SciELO (Scientific Electronic Library Online), patrocinando pela FAPESP (Fundação de Amparo à Pesquisa do Estado de São Paulo) e gerenciado pela Bireme (Centro Latino Americano e do Caribe de 
Informação em Ciências da Saúde), tendo também a partir de 2002 apoio do Conselho Nacional de Desenvolvimento Científico e Tecnológico - CNPQ. Iniciado em 1996 e operando regularmente desde junho de 1998, prevê ao longo de alguns anos, prover a comunidade científica brasileira de referencial semelhante ao JCR. É trabalho muito bonito, merece ser divulgado e ajudado por todos que de alguma forma trabalham com a ciência (www.bireme.br).

Seu sucesso inicial foi tão grande que, tendo sido criado para analisar somente periódicos brasileiros, passou a ser utilizado por outros sistemas de bibliotecas da América Latina e Península Ibérica. Atualmente indexa mais de 100 das 500 revistas brasileiras e está em permanente processo de expansão.

Em linhas gerais, os critérios para indexação de um periódico no SciELO são os mesmos do JCR, e não poderia ser diferente pois a qualidade da produção intelectual não tem limites territoriais. O rigor da forma (padrões internacionais), de regularidade (mínimo trimestralidade), de pontualidade (deve ser impressa até o mês de referência), de conteúdo (conter pesquisas com metodologia científica adequada e que sustente as conclusões), ter revisão feita por pareceristas independentes (peer-review), refletem a dificuldade que os editores vão enfrentar se quiserem nele ser incluídos.

A análise de obediência a estes preceitos é feita pela comunidade científica experiente em editoração em sua área específica e que, reunida sob a forma de comitês, analisam com rigor a obediência aos preceitos estabelecidos e sugerem ao SciELO a incorporação ou não periódico proposto.

Entendendo que precisaria entrar para esta base de dados, a revista $\mathrm{ABCD}$ se preparou por dois anos para cumprir todos os requisitos necessários para uma análise final vitoriosa. Seu corpo editorial freqüentou vários cursos e congressos no intuito de atualização e melhoria de qualidade editorial.

E deu certo!

Hoje o ABCD é veículo de informação científica moderno, ágil (procura publicar com grande presteza os artigos a ele dirigidos) e destinados à divulgação de todos os aspectos da gastroenterologia atual. É aberta à comunidade científica brasileira e internacional que milita na área e, importante, oferece-se como veículo de referência da pós-graduação brasileira apoiando os programas stricto sensu, em especial, no que diz respeito aos indicadores de publicações da massa crítica e "discente-autor" do sistema de avaliação da CAPES. Estes indicadores são importantes marcos, com pesos grandes no conceito final dos programas que, evidentemente, fazem esforço muito grande para obter as maiores notas.

Por regra geral da CAPES, ao entrar para o SciELO toda revista passa a ser Qualis A nacional, ou seja, a melhor posição conceitual em escala de A à C. Todo o elenco de publicações relatada no processo de avaliação assume, por conseguinte, o maior valor nacional possível no processo, o que ajuda o programa a se engrandecer perante seus pares.

Enfim, o ABCD está preparado para dar ao leitor a segurança de que é de qualidade. Se imaginariamente, estivermos em situação econômica que permita a aquisição de somente uma assinatura de periódico científico e procurando, dentre tantos outros bons, ASSINE O ABCD! e tenha certeza que estará adquirindo qualidade.

Angelita HABR-GAMA* 